\title{
Genetic Uniformity Among Isolates of Peronospora tabacina, the Tobacco Blue Mold Pathogen
}

\author{
Serenella A. Sukno, Amy M. Taylor, and Mark L. Farman
}

University of Kentucky, Department of Plant Pathology, S-305 Agricultural Sciences Center-North, Lexington 40546.

Current address of S. A. Sukno: 1832 Waterford Forest Circle, Cary, NC 27513.

Current address of A. M. Taylor: Department of Pharmacology and Toxicology, McGuire Hall, 112 E. Clay St., Richmond, VA 23298.

Accepted for publication 25 June 2002.

\begin{abstract}
Sukno, S. A., Taylor, A. M., and Farman, M. L. 2002. Genetic uniformity among isolates of Peronospora tabacina, the tobacco blue mold pathogen. Phytopathology 92:1236-1244.

As a first step toward analysis of genetic variation and population structure in Peronospora tabacina, we used a collection of random genomic DNA fragments to survey for restriction fragment length polymorphisms (RFLPs) in DNA from a collection of isolates from Kentucky and other tobacco-growing regions of the United States. Also included in the study were isolates from the wild tobacco species, Nicotiana repanda, and from ornamental tobacco, $N$. alata. In a preliminary survey using DNA from 10 pathogen isolates, no polymorphisms were detected at six single-copy DNA loci using 22 probe-enzyme combinations. Moderately repetitive and highly repetitive regions of the genome

which were from Kentucky. This resulted in the identification of very few additional polymorphisms, indicating that the population of $P$. tabacina that infects the Kentucky tobacco crop is genetically very homogeneous. The low level of polymorphism detected in this study overall, suggests that genetic variability may be lacking in $P$. tabacina populations throughout the United States. Two of the RFLP markers gave hybridization patterns that were consistent with $P$. tabacina being diploid. Frequencies of alleles at these loci and linkage disequilibrium between different marker loci indicated that genetic recombination does not occur frequently in the pathogen population. DNA polymorphisms that were identified in this study enabled us to differentiate the pathogen population into at least 10 haplotypes. One isolate was analyzed in detail and was shown to be genetically stable through several rounds of single-spore isolation and through several pathogenic cycles.
\end{abstract} were also remarkably similar between isolates, with only 6 of 15 different probes identifying genetic differences. Some of the polymorphic probes were then used to analyze a larger collection of isolates, most of
Additional keywords: biotroph, DNA fingerprinting, obligate parasite, transposon.
Peronospora tabacina is an oomycete pathogen that causes blue mold, a downy mildew disease of tobacco (Nicotiana tabacum). Prior to 1979 , blue mold was not a serious constraint to U.S. tobacco production, being mainly a seedbed disease that affected the production of tobacco transplants. Widespread epidemics were unusual. However, in 1979, the epidemiology of the disease changed and the U.S. and Canadian tobacco crops suffered extensive damage. All but 1 of the 14 tobacco growing states in the United States experienced significant losses (15). That year, the estimated losses for North America approached \$250 million (23). Since then, a number of widespread epidemics have occurred $(2,28)$. It has been proposed that the sudden emergence of blue mold as a serious disease of tobacco was due to wind-vectored immigration of a new pathogen race from Cuba $(1,15)$. However, due to the lack of molecular markers for $P$. tabacina, it has not been possible to characterize the pathogen population. Consequently, the reason for the rise of blue mold as one of the major constraints to field tobacco production has remained elusive.

Tobacco is an annual crop and therefore each year the blue mold pathogen must repopulate tobacco-growing regions. It is thought that the organism may overwinter in the United States on $N$. repanda, a wild tobacco species found in the Southwestern United States and Mexico $(19,30)$. Another possibility is that it survives as oospores in Florida and Georgia (11). Downy mildew isolates from $N$. repanda are morphologically indistinguishable from $P$. tabacina (30) and are capable of infecting $N$. tabacum in

Corresponding author: M. L. Farman; E-mail address: farman@uky.edu

Publication no. P-2002-0924-02R

(C) 2002 The American Phytopathological Society artificial inoculation assays (19). However, the exact relationship between downy mildew of wild tobacco and blue mold has, until now, been untested. In addition, it is not known if epidemics tend to be due to the amplification and spread of a single clone or if multiple inoculum sources are usually to blame. The purpose of this study was to identify restriction fragment length polymorphism (RFLP) markers in $P$. tabacina DNA, with the ultimate goal of investigating potential relationships between different pathogen isolates. In turn, it is hoped that this information will reveal the source of blue mold epidemics and enable identification and tracking of specific pathogen clones.

Very little is known about the genetics or molecular biology of P. tabacina. This is largely due to the difficulty of working with an obligate parasite. Nevertheless, a number of molecular markers have been applied to investigate genetic diversity in $P$. tabacina, including isoenzymes (4), internal transcribed spacer sequences (29), and random amplified polymorphic DNA (RAPD) markers (27). In addition, RAPDs and amplified fragment length polymorphisms have been used to study the related organism $P$. parasitica $(18,25)$. For $P$. tabacina, RAPD analysis resulted in detection of significant variability among isolates from the United States, Mexico, and Germany (27). However, variation was also detected between clones derived from a single spore, which suggested that the RAPD experiments may have been compromised by the presence of DNA from contaminating microbes (27). In an accompanying paper, we show that bacteria can be abundant even in filtered spores suspensions, as revealed by microscopic visualization and Southern hybridization analysis with bacterial probes (24). Therefore, due to the likelihood of contamination, studies of $P$. tabacina based on RAPD analysis are of questionable validity. 
To address this problem, we developed a collection of RFLP probes for this organism. The origin of each probe was confirmed and we showed that they do not hybridize to contaminating DNA present in the spore suspensions (24). The objective of this study was to use these probes to detect genetic variation among isolates of $P$. tabacina. This represents the first step toward studying the evolution and population biology of this organism. In addition, the ability to distinguish genetically different individuals will facilitate studies of blue mold epidemiology by enabling pathogen clones to be tracked. Improved understanding in these areas should lead to improved methods of controlling blue mold. In this paper, we report the results of experiments in which single-copy and repetitive DNA probes were used to identify polymorphic loci in genomic DNA samples from a representative collection of $P$. tabacina isolates. This study yielded information about genetic variability within $P$. tabacina populations and provided insight into their genetic structure.

\section{MATERIALS AND METHODS}

P. tabacina isolates. P. tabacina isolates used in this study came from naturally infected tobacco in transplant and field production systems and from wild and ornamental tobaccos. These isolates are maintained by the University of Kentucky, Department of Plant Pathology, and were supplied by W. Nesmith. Information about each isolate is provided in Table 1. Isolates were recovered from frozen storage by direct inoculation of tobacco plants following removal of dimethylsulfoxide (3). Prior to genetic analysis, all isolates were subjected to two rounds of singlespore isolation, as described in the accompanying paper (24). A number of steps were taken to minimize cross-contamination of isolates: (i) manipulation of different isolates at the same time was avoided; (ii) single-spore isolation was performed in a separate laboratory; and (iii) plants were inoculated in a HEPA-filtered containment hood (Model NU-425-600; Nu-aire, Plymouth, MN). The plants were transferred to another laboratory or a dedicated containment growth chamber for subsequent disease development. Sporulation was suppressed by maintaining the plants in the light at low humidity. Spores were allowed to develop only when the leaves were bagged. Spores were then harvested in the containment hood.

Host plants. For propagation of $P$. tabacina, burley tobacco cv. KY14 was used in all experiments. The procedures used for inoculation of tobacco plants and recovery of sporangiospores are described in detail in the accompanying paper (24).

Bacterial strains and plasmids. The $P$. tabacina DNA fragments used as probes were derived by extracting DNA from sporangiospore suspensions obtained from infected tobacco leaves. The DNA was digested with PstI. Fragments of 5 to $10 \mathrm{~kb}$ were selected and ligated into pBlueScript $\mathrm{KS} \mathrm{II}^{+}$(Stratagene, La Jolla, $\mathrm{CA}$ ). Clones were established, propagated, and maintained in Escherichia coli strain DH5 $\alpha$. All 20 of the probes used in this study were carefully characterized to confirm that they were derived from $P$. tabacina DNA. The details about the generation of the clones and the methods used to characterize them are provided in an accompanying paper (24).

Extraction of genomic DNA. Failure to purify $P$. tabacina spore preparations prior to extraction of DNA resulted in uneven hybridization signals from one sample to the next (24). This is because infected tobacco plants invariably harbor bacteria that contribute to the DNA pool. Therefore, to obtain even hybridization signals in the figures for this paper, spore suspensions were purified to remove bacterial contaminants prior to DNA extraction. This was accomplished by vacuum filtration of spore suspensions through a $0.8-\mu \mathrm{m}$ nitrocellulose membrane (47- $\mathrm{mm}$ diameter) (Millipore Corp., Bedford, MA). The spore mat was washed by passing $500 \mathrm{ml}$ of sterile Nanopure water through the filter. The spores $\left(\approx 10^{7}\right)$ were then recovered from the filters by vortex- ing in Nanopure $\mathrm{H}_{2} \mathrm{O}$, after which they were harvested by centrifugation $(10 \mathrm{~s}$ at $13,000 \times g)$. They were then washed in $1 \mathrm{ml}$ of $50 \mathrm{mM}$ EDTA, repelleted, and resuspended in $300 \mu \mathrm{l}$ of lysis buffer (50 mM Tris-HCl, $\mathrm{pH}$ 8.0, 50 mM EDTA, pH 8.0, $0.5 \mathrm{M} \mathrm{NaCl}, 1 \%$ sodium dodecyl sulfate (SDS), and $1 \%$ 2-mercaptoethanol). After the addition of $300 \mathrm{mg}$ of glass beads (425- to $600-\mu \mathrm{m}$ diameter) (Sigma-Aldrich, St. Louis), the suspension was vortexed vigorously for $60 \mathrm{~s}$ followed by cooling on ice for $60 \mathrm{~s}$. Vortexing and cooling was repeated nine times, after which the DNA was purified (Nucleon Phytopure Kit; Amersham Pharmacia Biotech, Piscataway, NJ) according to the manufacturer's instructions.

Southern hybridization analysis. One microgram of $P$. tabacina DNA was digested with one of eight six-base cutting restriction endonucleases (PstI, DraI, BamHI, HindIII, XhoI, EcoRI, $E c o$ RV, and KpnI). The digested DNA was resolved by electrophoresis in $0.5 \%$ SeaKem LE agarose gels (BioWhittaker Molecular Applications, Rockland, ME) made with $0.5 \times$ Tris-borateEDTA. Following electrophoresis, the gels were treated with depurination, denaturation, and neutralization solutions as described by Thornbury and Farman (26) and transferred by capillary transfer onto nylon membranes (Hybond- $\mathrm{N}^{+}$, Amersham Pharmacia Biotech). After transfer, the blots were dried for 1 to $2 \mathrm{~h}$ at $55^{\circ} \mathrm{C}$ and the DNA was cross-linked to the membrane by exposure to $1,200 \mu \mathrm{J}$ of UV light in a Spectrolinker (Spectronics Corp., Lincoln, NE).

Hybridization probes were obtained by excising plasmid inserts by Pst I digestion and separating them from the vector by agarose gel electrophoresis. Insert DNA was purified from the gel with the Qiaquick kit (Qiagen Inc., Valencia, CA) and were labeled with $\alpha^{32} \mathrm{P}-\mathrm{dCTP}$ by an oligolabeling kit (Amersham Pharmacia Bio-

TABLE 1. Peronopora tabacina isolates used in this study

\begin{tabular}{|c|c|c|}
\hline Isolate $^{\mathrm{a}}$ & Location & Host \\
\hline CT-96 & Connecticut & Nicotiana tabacum \\
\hline FL-95 & Florida & N. tabacum \\
\hline FL-97 & Alachua County, Florida & N. tabacum \\
\hline GA-98 & Grady County, Georgia & N. tabacum \\
\hline IN-98 & Jefferson County, Indiana & N. tabacum \\
\hline KY-79 & Mixed population, Kentucky & N. tabacum \\
\hline KY-93 & Mixed population, Kentucky & N. tabacum \\
\hline KY-95 & Mixed population, Kentucky & N. tabacum \\
\hline KY-Ch-98 & Christian County, Kentucky & N. tabacum \\
\hline KY-Cl-98 & Clark County, Kentucky & N. tabacum \\
\hline KY-Es-98 & Estill County, Kentucky & N. tabacum \\
\hline KY-Fa-98 & Fayette County, Kentucky & N. tabacum \\
\hline KY-Bo-99 & Boone County, Kentucky & N. tabacum \\
\hline KY-Clay-99 & Clay County, Kentucky & N. tabacum \\
\hline KY-Fa-99 & Fayette County, Kentucky & N. tabacum \\
\hline KY-Fa-99-2 & Fayette County, Kentucky & N. tabacum \\
\hline KY-Ha-98 & Harrison County, Kentucky & N. tabacum \\
\hline KY-Je-98 & Jessamine County, Kentucky & N. tabacum \\
\hline KY-Pu-98 & Pulaski County, Kentucky & N. tabacum \\
\hline KY-Sh-99 & Shelby County, Kentucky & N. tabacum \\
\hline KY-To-98 & Todd County, Kentucky & N. tabacum \\
\hline KY-War-98 & Warren County, Kentucky & N. tabacum \\
\hline KY-Was-98 & Washington County, Kentucky & N. tabacum \\
\hline KY-Wo-98 & Woodford, County, Kentucky & N. tabacum \\
\hline PA-98 & Lancaster County, Pennsylvania & N. tabacum \\
\hline TN-98 & Trousdale County, Tennessee & N. tabacum \\
\hline TN-99 & Montgomery County, Tennessee & N. tabacum \\
\hline VA-98 & Virginia & N. tabacum \\
\hline WI-98 & Rock County, Wisconsin & N. tabacum \\
\hline KY-Bou-96 & Bourbon County, Kentucky & N. alata \\
\hline TX-98-1 & Uvalde County, Texas & N. repanda \\
\hline TX-98-2 & Uvalde County, Texas & N. repanda \\
\hline TX-98-3 & Uvalde County, Texas & N. repanda \\
\hline TX-98-4 & Uvalde County, Texas & N. repanda \\
\hline
\end{tabular}

a Names indicate the state and year in which each isolate was collected. Isolates recovered in the same year are further identified according to the county from which they came. 
tech). Unincorporated nucleotides were removed by centrifugation through a spin column containing Sephadex G-50 (Amersham Pharmacia Biotech). Conditions for prehybridization, hybridization, and posthybridization washes were conducted according to

A)
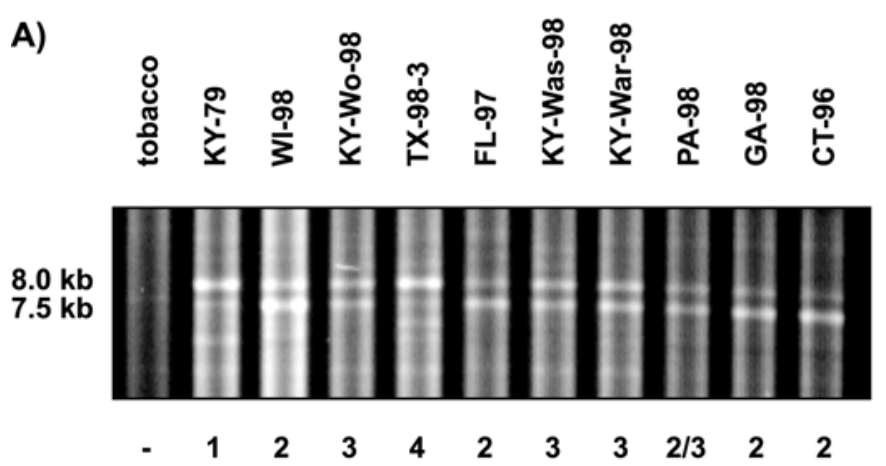

B)

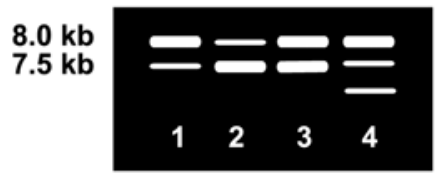

Fig. 1. Polymorphisms in the Peronospora tabacina ribosomal repeat. One microgram of DNA from each isolate was digested with PstI and electrophoresed in a $0.5 \%$ agarose gel. A, Digital image of the ethidium bromidestained gel illuminated with UV light. Isolate names are shown above the respective lanes. Molecular sizes of relevant fragments are indicated on the left. The rDNA haplotypes are noted beneath each lane (PA-98 showed an intermediate pattern). These were assigned as described according to the schematic shown in B. The thicker lines represent DNA bands that fluoresced with greater intensity under UV light.
Thornbury and Farman (26). After washing, the membranes were wrapped in Saran Wrap plastic film (Dow Brands L.P., Indianapolis) and exposed to PhosphorImager screens (Amersham Pharmacia Biotech) for 1 to 5 days depending on the strength of the hybridization signals. Screens were scanned in a Molecular Dynamics PhosphorImager (Model 445 SI; Amersham Pharmacia Biotech) using a pixel resolution of $176 \mu \mathrm{m}$. Resulting data were quantitated with ImageQuaNT 4.0 software (Amersham Pharmacia Biotech) with local average background correction. After exposure, blots were stripped in a preheated $\left(110^{\circ} \mathrm{C}\right)$ solution of $0.5 \times \mathrm{SDS}$ for $20 \mathrm{~min}$, washed in $0.1 \times \mathrm{SDS} / 0.1 \% \mathrm{SDS}$ solution at $65^{\circ} \mathrm{C}$ overnight, and dried and stored between paper towels.

\section{RESULTS}

Purification of $P$. tabacina DNA for subcloning and Southern hybridization analysis. While developing the probes for this study, we showed that it is not strictly necessary to purify spores prior to DNA extraction (24). However, use of crude spore suspensions resulted in significant lane-to-lane variation in hybridization signals. Therefore, to obtain publication-quality figures for this paper, we filtered spores to remove bacterial contaminants prior to extraction of genomic DNA. In the early stages of the project, we used DNA isolation methods that employ phenol extraction $(7,17,20)$, because this reagent is very efficient at disintegrating the spore walls (M. L. Farman, unpublished data). However, these methods resulted in low yields of poor quality DNA (4 to $10 \mu \mathrm{g}$ per $10^{6}$ spores) that was difficult to dissolve and hard to quantify reproducibly and which was resistant to restriction digestion (S. A. Sukno and M. L. Farman, unpublished data). Use of glass beads to break open the cells followed by purification with the Nucleon Phytopure kit resulted in up to ninefold higher yields of DNA ( 15 to $45 \mu \mathrm{g}$ per $10^{6}$ spores or 5 to $15 \mathrm{pg}$ per spore) that was of high quality. Spores collected from four or five leaves of a single, heavily infected tobacco plant

TABLE 2. Results of restriction fragment length polymorphism analysis with low-copy, moderately repetitive, and highly repetitive DNA probes

\begin{tabular}{|c|c|c|c|c|c|c|c|c|c|c|c|c|}
\hline \multirow[b]{2}{*}{ Probe $^{a}$} & \multirow[b]{2}{*}{ Size $(k b)^{b}$} & \multirow{2}{*}{$\begin{array}{l}\text { Similarity } \\
(\text { BLASTx })^{\mathrm{c}}\end{array}$} & \multirow[b]{2}{*}{ E value $^{\mathrm{d}}$} & \multicolumn{8}{|c|}{ Enzyme $^{\mathrm{e}}$} & \multirow[b]{2}{*}{ Polymerase } \\
\hline & & & & $\mathrm{P}$ & $\mathrm{D}$ & B & $\mathrm{H}$ & $X$ & $\mathrm{E}$ & EV & $\mathrm{K}$ & \\
\hline Low copy & & & & & & & & & & & & No \\
\hline A4 & 4.2 & n.s. & & 0 & 0 & 0 & 0 & $\ldots$ & 0 & 0 & 0 & No \\
\hline E1 & 2.9 & n.s. & & 0 & 0 & $\ldots$ & $\ldots$ & $\ldots$ & $\ldots$ & $\ldots$ & $\ldots$ & No \\
\hline E6 & 3.2 & n.s. & & 0 & 0 & $\ldots$ & $\ldots$ & $\ldots$ & $\ldots$ & $\ldots$ & $\ldots$ & No \\
\hline $\mathrm{J} 12$ & 6 & n.s. & & 0 & $\ldots$ & $\ldots$ & $\ldots$ & $\ldots$ & $\ldots$ & $\ldots$ & $\ldots$ & No \\
\hline K12 & 5 & n.s. & & 0 & 0 & $\ldots$ & $\ldots$ & $\ldots$ & $\ldots$ & $\ldots$ & $\ldots$ & No \\
\hline M11 & 5 & SNF2 protein (14) & $\mathrm{e}^{-24}$ & 0 & 0 & 0 & 0 & 0 & 0 & 0 & 0 & No \\
\hline \multicolumn{13}{|l|}{ Moderately repetitive } \\
\hline $\mathrm{K} 1$, I9 & 5 & n.s. & & 1 & 3 & 0 & 1 & 0 & 1 & 0 & 1 & Yes \\
\hline $\mathrm{K} 8$ & 5 & n.s. & & 1 & 2 & $\ldots$ & 1 & $\ldots$ & $\ldots$ & $\ldots$ & $\ldots$ & Yes \\
\hline Telomere & 1.6 & $(\mathrm{TTTAGGG})_{\mathrm{n}}$ & & 5 & 3 & 0 & 3 & $\cdots$ & 1 & 1 & 2 & Yes \\
\hline \multicolumn{13}{|l|}{ Highly repetitive } \\
\hline A7, D3 & $2.8,2$ & Retroelement & 0.05 & 0 & 0 & $\ldots$ & $\ldots$ & $\ldots$ & $\ldots$ & $\ldots$ & $\ldots$ & No \\
\hline A9 & 1.8 & n.s. & & 0 & 0 & $\ldots$ & $\ldots$ & $\ldots$ & $\ldots$ & $\ldots$ & $\ldots$ & No \\
\hline C5, J10, K5, K12, L9 & $2.8,4.5,5.1,5,5.2$ & Retroelement & $5 e^{-20}$ & 0 & 0 & 0 & $\ldots$ & $\ldots$ & $\ldots$ & $\ldots$ & $\ldots$ & No \\
\hline I4 & 5.5 & n.s. & & 0 & $\ldots$ & $\ldots$ & $\ldots$ & $\ldots$ & $\ldots$ & $\ldots$ & $\ldots$ & No \\
\hline I7, K11 & 6,6 & n.s. & & 0 & 0 & $\ldots$ & $\ldots$ & $\ldots$ & $\ldots$ & $\ldots$ & $\ldots$ & No \\
\hline $\mathrm{J} 4$ & 6 & n.s. & & 0 & $\ldots$ & $\ldots$ & $\ldots$ & $\ldots$ & $\ldots$ & $\ldots$ & $\ldots$ & No \\
\hline L3 & 5.1 & n.s. & & 0 & $\ldots$ & $\ldots$ & $\ldots$ & $\ldots$ & $\ldots$ & $\ldots$ & $\ldots$ & No \\
\hline L8 & 5.8 & Retroelement & $3 e^{-22}$ & 0 & 0 & 0 & 0 & $\ldots$ & $\ldots$ & 0 & $\ldots$ & No \\
\hline L11 & 5.7 & n.s. & & 0 & 0 & 0 & 0 & $\ldots$ & $\ldots$ & $\ldots$ & $\ldots$ & No \\
\hline L10, L12 & 5.5 & Retroelement & $6 e^{-29}$ & 6 & 0 & 0 & 0 & $\ldots$ & 0 & $\ldots$ & 0 & Yes \\
\hline M4 & 5.2 & n.s. & & 0 & $\ldots$ & $\ldots$ & $\ldots$ & $\ldots$ & $\ldots$ & $\ldots$ & $\ldots$ & No \\
\hline rDNA & & Ribosomal repeat & & 3 & $\ldots$ & $\ldots$ & $\ldots$ & $\ldots$ & $\ldots$ & $\ldots$ & $\ldots$ & Yes \\
\hline
\end{tabular}

${ }^{a}$ Probes that gave identical fingerprints are listed together, separated by commas.

b Corresponds to plasmid insert size.

c Most significant hit obtained by searching the GenBank database; n.s. = no similarity.

d The expect (E) value is a parameter that describes the number of hits one can "expect" to see just by chance when searching a database of a particular size.

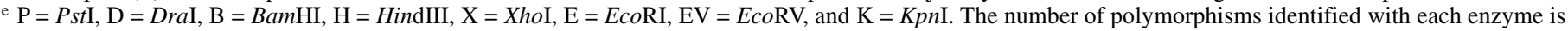
recorded; ... indicates the enzyme was not tested. 
yielded sufficient DNA for most of the analyses performed in this study.

Selection of isolates. For the initial polymorphism screens, 10 isolates were selected from the P. tabacina culture collection in the laboratory of W. Nesmith at the University of Kentucky. Isolate selection was based on criteria that were expected to favor the identification of genetic variation. For example, the initial set of 10 isolates came from different tobacco-growing regions of the United States. They were collected from 1979 to 1999 (most being from 1996 to 1999); one isolate (TX-98-3) came from wild tobacco ( $N$. repanda) in Texas; and there was variation in phenotypic characteristics such as sensitivity to the fungicide metalaxyl (W. Nesmith, personal communication). Once polymorphic markers were identified, they were used to investigate variation with an expanded isolate collection comprised largely of additional isolates from Kentucky. The reason for the bias toward local isolates was to assign molecular haplotypes to isolates associated with particular disease epidemics.

Ribosomal DNA polymorphisms. Following electrophoretic separation in agarose gels, ethidium bromide staining of restriction enzyme-digested $P$. tabacina DNA resulted in the appearance under UV light of distinctive repetitive DNA banding patterns. Some of these repetitive bands were polymorphic in the PstI-digested samples (Fig. 1A). Specifically, repetitive DNA bands with molecular sizes of 8.0 and $7.5 \mathrm{~kb}$ varied in relative intensities between isolates. The abundance of these repetitive fragments, combined with their large molecular size, suggested that they were derived from the ribosomal repeat. This was confirmed by probing a Southern blot of the gel using a ribosomal DNA probe from Neurospora crassa (6), which resulted in strong hybridiza- tion to these bands (data not shown). Four different rDNA haplotypes were visible in the gel in Figure 1A. These are schematically represented in Figure 1B. Haplotype 1 was present in just one isolate (KY-79), four isolates possessed haplotype 2 (WI-98, FL97, GA-98, and CT-96), three had haplotype 3 (KY-Wo-98, KYWar-98, and KY-Was-98), and TX-98-3 had haplotype 4. The final isolate, PA-98, had an ambiguous haplotype that appeared to be intermediate between 2 and 3 (Fig. 1A).

Identification of RFLPs in $P$. tabacina DNA using singlecopy probes. To survey for RFLPs at single-copy genomic loci, DNA from $10 P$. tabacina isolates was digested with various restriction enzymes, electrophoresed, blotted to membranes, and probed with the inserts of confirmed clones of $P$. tabacina DNA (24). A total of 22 probe-enzyme combinations were tested. All combinations produced monomorphic hybridization patterns across the 10 isolates that were examined (Table 2). A representative result obtained with probe A4 is shown in Figure $2 \mathrm{~A}$. All of the probes were PstI subclones, and therefore, when they were hybridized with PstI-digested genomic DNA, we expected that at least one signal would have a molecular size corresponding to that of the plasmid insert. This prediction was met and most singlecopy probes hybridized to a single PstI fragment of the expected size. However, three probes revealed additional signals (Fig. 2A), suggesting that the P. tabacina genome has a number of duplications or that the organism is diploid and heterozygous for some loci.

Repetitive DNA fingerprinting. The monomorphic hybridization patterns obtained with the single-copy probes suggested that there is very little genetic diversity among the $P$. tabacina isolates that were selected. To explore this further, the same collection of
A)
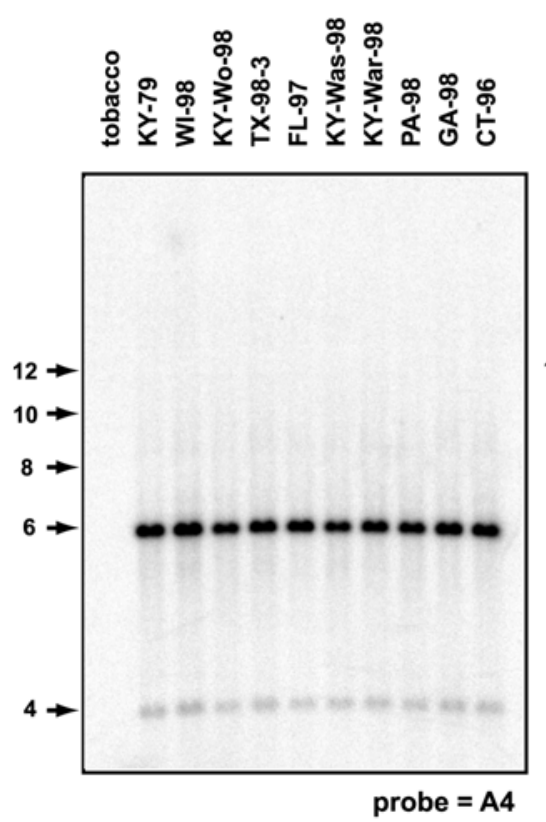

B)
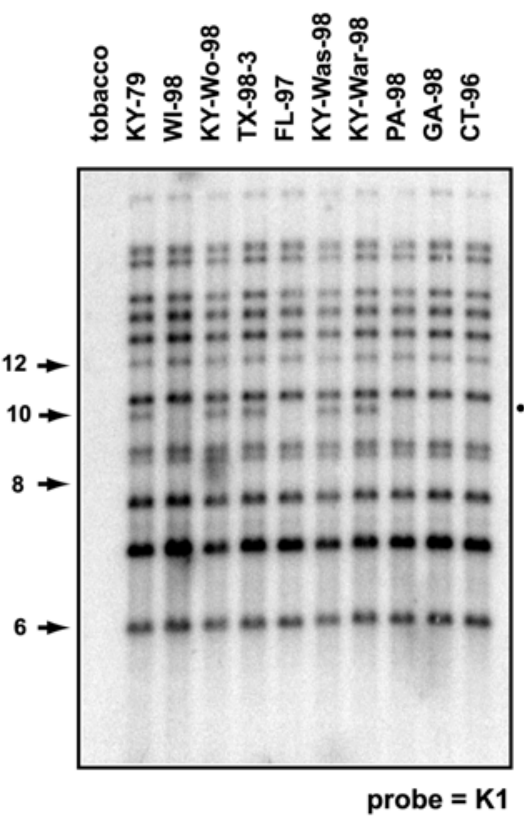

C)
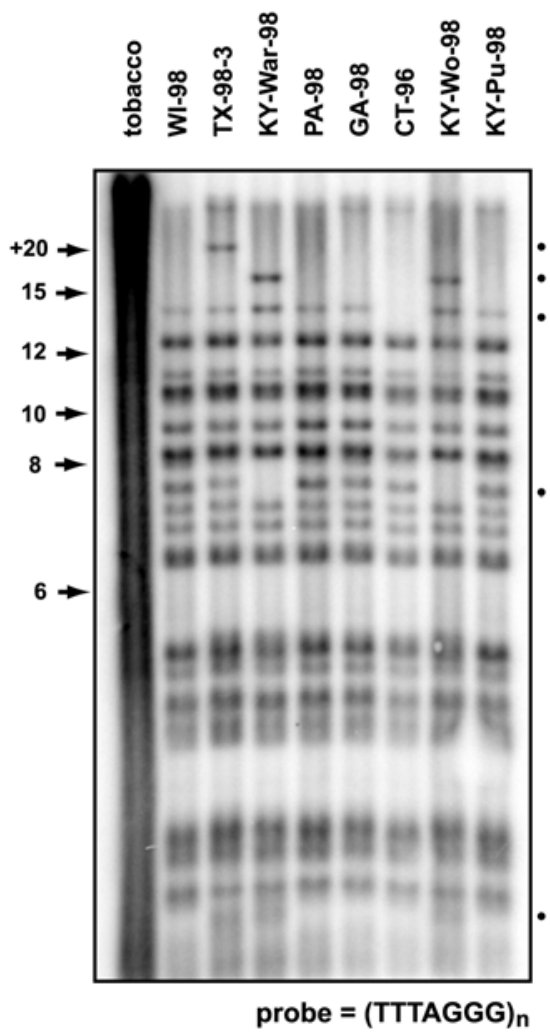

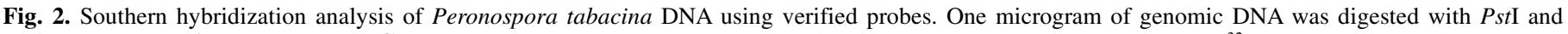

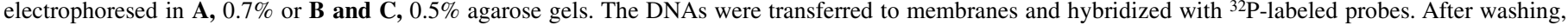

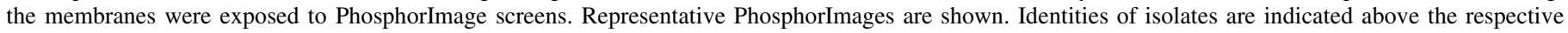

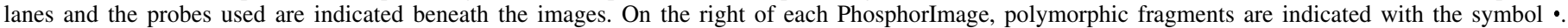
Arrows on the left indicate molecular sizes in kilobases. 
isolates was analyzed by repetitive DNA fingerprinting, which enables many more loci to be surveyed per experiment. Three moderately repetitive and 18 highly repetitive probes were used for these analyses. Also included was a probe based on the telomere sequence of Phytophthora infestans [(TTTAGGG)n] (16).

By definition, the repetitive probes hybridized to multiple genomic loci (Fig. 2, panels B and C). There was a certain degree of redundancy in the repetitive probe collection revealed by the fact that some probes yielded the same fingerprint pattern (data not shown). In most cases, however, the redundant clones had different insert sizes (Table 2), indicating that they were derived independently. Using 28 probe-enzyme combinations, only four of the repetitive probes (K1/I9 [Fig. 2B], K8, and L12) identified clear polymorphisms (Table 2 ). With the moderately repetitive probes $\mathrm{K} 1 / \mathrm{I} 9$ and K8, RFLPs were detected in five of eight different digests. Moreover, most of these polymorphisms were independent, indicated by differences in the distribution of alleles among the various isolates. For example, the alleles for the tel-P1, tel-D1, tel-D2, and tel-K1 markers are not distributed identically among the different isolates (Table 3).

The "telomere" probe also produced moderately repetitive fingerprints (Fig. 2C), which was consistent with its hybridizing to telomeric sequences in $P$. tabacina. As with the other moderately repetitive probes, polymorphisms were detected in most enzyme digests (Table 2), although in some cases it appeared that the same polymorphic locus was revealed in different enzyme digests. This was because some of the RFLPs that were identified by different enzymes showed identical distributions among isolates (tel-P1 and tel-K1) (Table 3). With all of the repetitive probes, only a very small fraction of the fragments in the fingerprints were actually polymorphic. This was true also, for the $P$. tabacina isolate from $N$. repanda, which had nearly identical fingerprints to the isolates from commercial tobacco (Figs. 2 to 4). The distribution of marker K1-1D implies that the isolate from $N$. repanda is more closely related to those from Kentucky than to the isolates from the other states. However, the telomeric markers reveal that these relationships are not so straightforward, because the Kentucky isolates KY-War-98 and KY-Wo-98 have a different telomere fingerprint to KY-Pul-98, which itself is more similar to the isolates from the other states (Fig. 2C).

The RFLP patterns produced by the moderately repetitive probes $\mathrm{K} 1$ and $\mathrm{K} 8$ provided evidence that $P$. tabacina, like other members of the Peronosporales, is diploid. With $\mathrm{K} 1$, four isolates (Fig. 3A, indicated with asterisks) gave hybridization signals of equivalent intensities at molecular sizes of 8 and $7.5 \mathrm{~kb}$. However, in all the remaining isolates, the 8-kb signal was absent and in each case the 7.5-kb signal was of double intensity, as judged relative to the $7-\mathrm{kb}$ fragment immediately beneath it (Fig. 3A). This result is consistent with the 8 - and $7.5-\mathrm{kb}$ fragments being polymorphic alleles at a single locus. A similar observation was made with probe $\mathrm{K} 8$, which hybridized to fragments of 10.5 and $11 \mathrm{~kb}$. Most isolates possessed fragments of one size or the other, except for CT-96, which possessed both (Fig. 3B), and KY-79, which had neither (data not shown). The presence of both fragments in CT-96, together with their reduced signal intensity in the presumed heterozygotes, is an indication that this isolate is heterozygous for the K8-1P locus.

Genetic characterization of a larger collection of $\boldsymbol{P}$. tabacina isolates. Eight of the RFLPs identified in the preliminary survey were subsequently used to examine the distribution of the various

TABLE 3. Alleles at restriction fragment length polymorphism (RFLP) loci for 30 isolates of Peronospora tabacina

\begin{tabular}{|c|c|c|c|c|c|c|c|c|c|}
\hline \multirow[b]{2}{*}{ Isolate } & \multicolumn{8}{|c|}{ RFLP marker ${ }^{\mathrm{a}}$} & \multirow[b]{2}{*}{ Haplotype ${ }^{b}$} \\
\hline & $\mathrm{rDNA}^{\mathrm{c}}$ & $\mathrm{L} 1-\mathrm{D} 1^{\mathrm{d}}$ & K1-P1 & K8-P1 & tel-P1 & tel-D1 & tel-D2 & tel-K1 & \\
\hline KY-95 & 2 & - & 0 & 1,1 & 1,1 & 1 & 1 & 1 & A \\
\hline FL-97 & 2 & 1,1 & 0 & 1,1 & 1,1 & 1 & 1 & 1 & A \\
\hline KY-79 & 1 & 1,1 & 1 & 3,3 & 1,1 & 0 & 0 & 1 & B \\
\hline FL-96 & 2 & 1,1 & 0 & 1,1 & 1,1 & 1 & 0 & 1 & $\mathrm{C}$ \\
\hline KY-Cl-98 & 2 & - & 0 & 1,1 & 1,1 & 1 & 0 & - & $\mathrm{C}$ \\
\hline KY-Es-98 & 2 & - & 0 & 1,1 & 1,1 & 1 & 0 & - & $\mathrm{C}$ \\
\hline KY-Ha-98 & 2 & 1,1 & 0 & 1,1 & 1,1 & 1 & 0 & - & $\mathrm{C}$ \\
\hline KY-Pu-98 & 2 & - & 0 & 1,1 & 1,1 & 1 & 0 & - & $\mathrm{C}$ \\
\hline KY-Je-98 & 2 & - & 0 & 1,1 & 1,1 & 1 & 0 & 1 & $\mathrm{C}$ \\
\hline PA-98 & $2(3)^{e}$ & 1,1 & 0 & 1,1 & 1,1 & 1 & 0 & 1 & $(C)^{e}$ \\
\hline WI-98 & 2 & 1,1 & 0 & 1,1 & 1,1 & 1 & 0 & 1 & $\mathrm{C}$ \\
\hline TN-99 & 2 & 1,1 & 0 & 1,1 & 1,1 & 1 & 0 & 1 & $\mathrm{C}$ \\
\hline KY-Fa-99 & 2 & 1,1 & 0 & 1,1 & 1,1 & 1 & 0 & - & $\mathrm{C}$ \\
\hline KY-93 & 3 & - & 1 & 2,2 & 2,2 & 0 & 0 & 0 & $\mathrm{D}$ \\
\hline KY-Ch-98 & 3 & 1,2 & 1 & 2,2 & 2,2 & 0 & 0 & 0 & $\mathrm{D}$ \\
\hline KY-War-98 & 3 & 1,2 & 1 & 2,2 & 2,2 & 0 & 0 & 0 & $\mathrm{D}$ \\
\hline KY-Was-98 & 3 & 1,2 & 1 & 2,2 & 2,2 & 0 & 0 & 0 & $\mathrm{D}$ \\
\hline KY-Wo-98 & 3 & 1,2 & 1 & 2,2 & 2,2 & 0 & 0 & 0 & $\mathrm{D}$ \\
\hline KY-Fa-98 & 2 & - & 0 & 1,2 & 1,1 & 1 & 0 & 1 & $\mathrm{E}$ \\
\hline CT-96 & 2 & 1,1 & 0 & 1,2 & 1,1 & 1 & 0 & 1 & $\mathrm{E}$ \\
\hline KY-Sh-99 & 1 & - & 1 & 2,2 & 2,2 & 0 & 0 & 0 & $\mathrm{~F}$ \\
\hline KY-Clay-99 & 1 & - & 1 & 2,2 & 2,2 & 0 & 0 & 0 & $\mathrm{~F}$ \\
\hline FL-95 & $2(3)^{e}$ & - & 1 & 1,2 & 1,1 & 1 & 0 & 1 & $\mathrm{G}$ \\
\hline IN-98 & 2 & - & 0 & 1,1 & 1,1 & 1 & 0 & 1 & $\mathrm{H}$ \\
\hline GA-98 & 2 & 1,1 & 0 & 1,1 & 1,1 & 1 & 0 & 1 & $\mathrm{H}$ \\
\hline TX-1-98 & 4 & - & 1 & 2,2 & 1,1 & 0 & 0 & 1 & I \\
\hline TX-2-98 & 4 & 1,2 & 1 & 2,2 & 1,1 & 0 & 0 & 1 & I \\
\hline TX-3-98 & 4 & 1,2 & 1 & 2,2 & 1,1 & 0 & 0 & 1 & I \\
\hline TX-4-98 & - & 1,2 & 1 & 2,2 & 1,1 & 0 & 0 & - & I \\
\hline KY-Fay-99-2 & 1 & 1,2 & 1 & 2,2 & 1,1 & 0 & 0 & 1 & $\mathrm{~J}$ \\
\hline
\end{tabular}

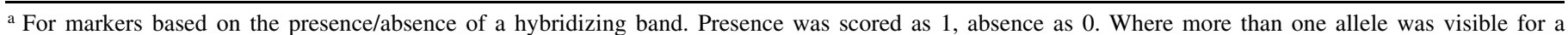

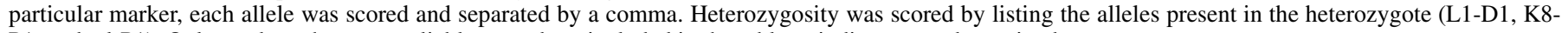
$\mathrm{P} 1$, and tel-P1). Only markers that were reliably scored are included in the table; - indicates not determined.

${ }^{b}$ Isolates with identical RFLP profiles have the same (multilocus) haplotype.

${ }^{c}$ Numbers in the rDNA column represent rDNA haplotypes as opposed to alleles.

${ }^{\mathrm{d}}$ Markers are named using the format: probe-enzyme, marker fragment.

e rDNA haplotype was ambiguous (Fig. 1). 
marker alleles among a larger collection of 30 P. tabacina isolates. For most of the markers, analysis of additional isolates failed to reveal new alleles, as illustrated by the result obtained with marker K8-P1 (Fig. 4). After each polymorphic marker was scored, multilocus haplotypes were defined for each isolates based on the alleles that were present at the individual marker loci. This resulted in the differentiation of at least 10 distinct haplotypes (A to $\mathrm{J}$ ) within the modest collection of isolates analyzed in this study (Table 3).

If one considers the allele frequencies for the K1-D1 and K8-P1 markers among the 30 isolates, in neither case are they in HardyWeinberg equilibrium. Specifically, for K1-D1, one homozygote class $(2,2)$ was missing, and for both K1-D1 and K8-P1, heterozygotes were too infrequent (Table 3). Pairwise comparisons of genotypes at different loci reveals that there is a certain degree of linkage disequilibrium between some pairs of markers. For example, markers K8-P1 and tel-P1 have identical genotypes in most of the isolates examined (Table 3). Similar associations are evident between other pairs of isolates (Table 3). However, it should be noted that no two markers exhibited a perfect correlation and consequently, some isolates had recombinant genotypes (Table 3).

Investigation of genetic variation between single-spore isolates. Many of the isolates analyzed in this study were genetically different from one another, as revealed by their resolution into at least 10 distinct RFLP haplotypes (Table 3). Studies of P. tabacina are usually performed using populations of spores collected from one or a few infected leaves. Therefore, we performed an experiment to determine if one of these mixed populations might be comprised of genetically different individuals. Ten single-spore lineages were established from the KY-Wo-98 spore suspension that came from a naturally infected leaf in Woodford County, Kentucky. DNA was extracted and fingerprinted with the K1 probe. The results of this study showed that all 10 isolates had identical fingerprints (data not shown), suggesting that the original leaf was infected by a single $P$. tabacina clone or that this clone predominated in the infection.

A previous study of genetic variability in P. tabacina found that RAPD profiles changed from one single-spore generation to the next (27). It was not clear whether this was a result of genetic instability in the pathogen or if the spore suspensions were contaminated with other organisms (27). We sought to address this issue by repeating these experiments using single-copy RFLP analysis and repetitive DNA fingerprinting to detect genetic changes occurring from one generation to the next. The KY-Wo-98 isolate was subjected to 10 successive cycles of single-sporing. At each generation, the single-spore isolate was propagated in tobacco to produce spores for DNA extraction and for the next round of single-spore isolation. The DNA samples were digested with PstI, electrophoresed, and Southern blotted before being subjected to hybridization analysis. One single-copy probe was used (M11) along with the repetitive probes K1 and L12. None of the probes detected any changes in the hybridization patterns in DNA from different single-spore generations (data not shown). Equivalent results were obtained when this isolate was serially passaged through plants without single-spore isolations between each round of infection (data not shown). The fact that no genetic changes were detected through 10 successive disease cycles, which would correspond to several hundred nuclear generations, provides an indication that P. tabacina is genetically stable.

\section{DISCUSSION}

In this paper, we report on analysis of genetic variation among isolates of $P$. tabacina collected in Kentucky and several other locations in the United States. Using both single-copy and repetitive DNA probes that had previously been confirmed to be true $P$. tabacina DNA clones (24), we surveyed hundreds of genomic loci for polymorphisms. Single-copy probes failed to identify RFLPs among the isolates included in this study, indicating that there is limited genetic diversity in single-copy regions of the $P$. tabacina genome. In contrast, polymorphisms were readily identified with each of the moderately repetitive clones that were used (K1/I9, $\mathrm{K} 8$, and the telomere probe). In the light of the latter results, it is surprising that only one of the highly repetitive probes revealed visible polymorphisms, because these probes surveyed many more genomic loci. Of the 28 probe-enzyme combinations that were tested using the highly repetitive probes, only one combination (L12-PstI) produced visible polymorphisms (Fig. 2C; Table 2). This trend was also noted in a similar study of Phytophthora infestans (8). In the case of P. tabacina, it is not clear whether the moderately repetitive loci are actually more polymorphic or if the complex hybridization signals produced by the highly repetitive probes tend to obscure a small number of polymorphic fragments. Needless to say, the extremely low level of polymorphism revealed in our study provides a strong indication that isolates of $P$. tabacina that occur in Kentucky are genetically very similar. The lack of diversity among Kentucky isolates is likely reflective of the diversity over a broader geographic area because the pathogen does not overwinter in this state and must therefore be introduced from elsewhere. Although we did not analyze an extensive collection of isolates from other tobacco-growing regions of the United

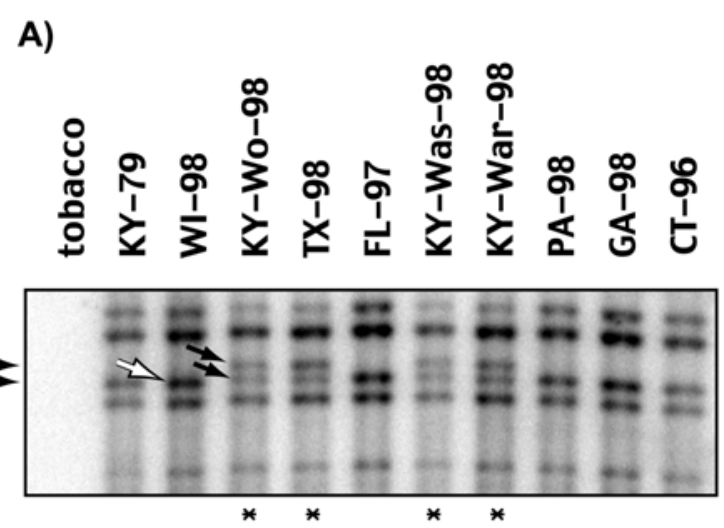

B)
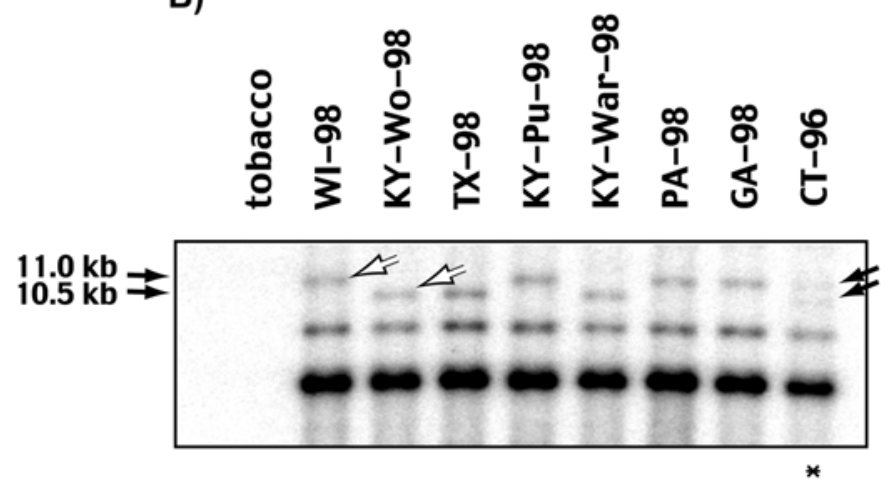

Fig. 3. Polymorphisms identified by the moderately repetitive probes $\mathrm{K} 1$ and K8. One microgram of DNA from each isolate was digested with restriction enzyme and electrophoresed in a $0.5 \%$ agarose gel. DNA was transferred to membranes and hybridized with ${ }^{32} \mathrm{P}$-labeled probes. The membranes were washed and exposed to PhosphorImager screens. Shown are representative PhosphorImages: A, DraI-digested DNAs probed with K1. The marker illustrated is K1-D1; and $\mathbf{B}$, Pst I-digested DNAs probed with K8, resulting in identification of marker K8-P1. Identities of isolates are indicated above the respective lanes and tobacco DNA was included as a control (lane 1). Hybridization signals representing homozygous restriction fragment length polymorphism loci are indicated by white arrows superimposed on the image; a heterozygous locus is indicated with black arrows. Isolates that are heterozygous for markers K1-D1 and K8-P1 are indicated by *. Lane 1 contains tobacco DNA as a control. 
States, the fact that all of the isolates we examined were so strikingly similar, regardless of tobacco host or place and year of isolation, suggests that the pathogen population might have limited diversity throughout the United States as a whole. In this regard, it is worth mentioning that isolates from Tennessee and Virginia were identical to the isolates analyzed in this study in terms of their highly repetitive DNA fingerprints (data not shown).

The lack of polymorphism was particularly significant with regard to the $P$. tabacina isolates from $N$. repanda (TX98-1 and TX98-3) and N. alata (KY-Bou-96). These isolates had repetitive DNA fingerprints that were virtually indistinguishable from those produced by isolates from $N$. tabacum (Figs. 2 and 4). The significance of the ribosomal DNA polymorphism in the isolates from $N$. repanda is unclear due to the small number of isolates analyzed. However, the similarity at all other loci provides support for the hypothesis that $N$. repanda in Mexico is a potential reservoir for the tobacco blue mold pathogen $(19,30)$.

The amount of genetic variation measured in the present study is similar to that found by Edreva et al., who detected very little isoenzyme variation among a collection of $P$. tabacina isolates from France and Bulgaria (4). This contrasts with the results obtained by Wiglesworth, where different RAPD profiles were produced by $P$. tabacina isolates from Mexico, Germany, and the United States (27). It is possible that Wiglesworth detected more variation due to the broader geographic area from which the isolates were sampled. However, the fact that differences were also detected between clonal populations of spores, suggested that the RAPD analysis may have been compromised by the presence of contaminating DNA (27). Using RFLP markers, we were unable to detect any variation between clones despite surveying a much larger number of marker loci. This, together with the fact that bacterial contamination of $P$. tabacina spores is a pervasive problem (24), strongly suggests that contamination had indeed affected the previous RAPD analysis.
The low level of genetic variability in P. tabacina is surprising because a large proportion of its genome is comprised of repetitive DNA. In our preliminary survey of 85 probes, 47 were derived from $P$. tabacina and 31 of these $(66 \%)$ contained repetitive sequences (S. Sukno and M. Farman, unpublished data). This is similar to the repetitive DNA contents of other oomycetes such as Bremia lactucae, which contains $\approx 65 \%$ repetitive DNA (5), and Phytophthora infestans, which contains $\approx 60 \%$ (8). Nucleotide sequences of 10 repetitive $P$. tabacina clones showed similarity to gypsy- and copia-like retroelements (Table 2), suggesting that much of the repeated DNA in the P. tabacina genome is comprised of transposon-like sequences. This would normally be expected to result in high levels of genomic variation. One possibility is that the transposons are no longer active in $P$. tabacina. However, even in the absence of transposition, ectopic recombination between repeated DNA sequences $(12,22)$ is expected to result in a significant amount of genome rearrangement. Therefore, the most likely explanation for the low level of polymorphism among the $P$. tabacina isolates analyzed in this study is that the population has experienced a recent bottleneck, resulting in a reduction of genetic diversity.

Bottlenecks can occur when a new pathogen race evolves from a small number of individuals, or when these individuals immigrate or are introduced into a new location (13). Unfortunately, the lack of knowledge regarding rates of genetic change in $P$. tabacina means that it is not possible to determine when such events might have occurred. Knowledge of the genetic makeup of $P$. tabacina isolates found in other countries or continents may provide important clues as to whether the predominant epidemic population in the United States immigrated or was introduced from elsewhere. Unfortunately, we were unable to address this possibility in the current project due to the strict quarantine conditions required for introduction and the study of exotic $P$. tabacina isolates in the United States and especially at the University of Kentucky, which
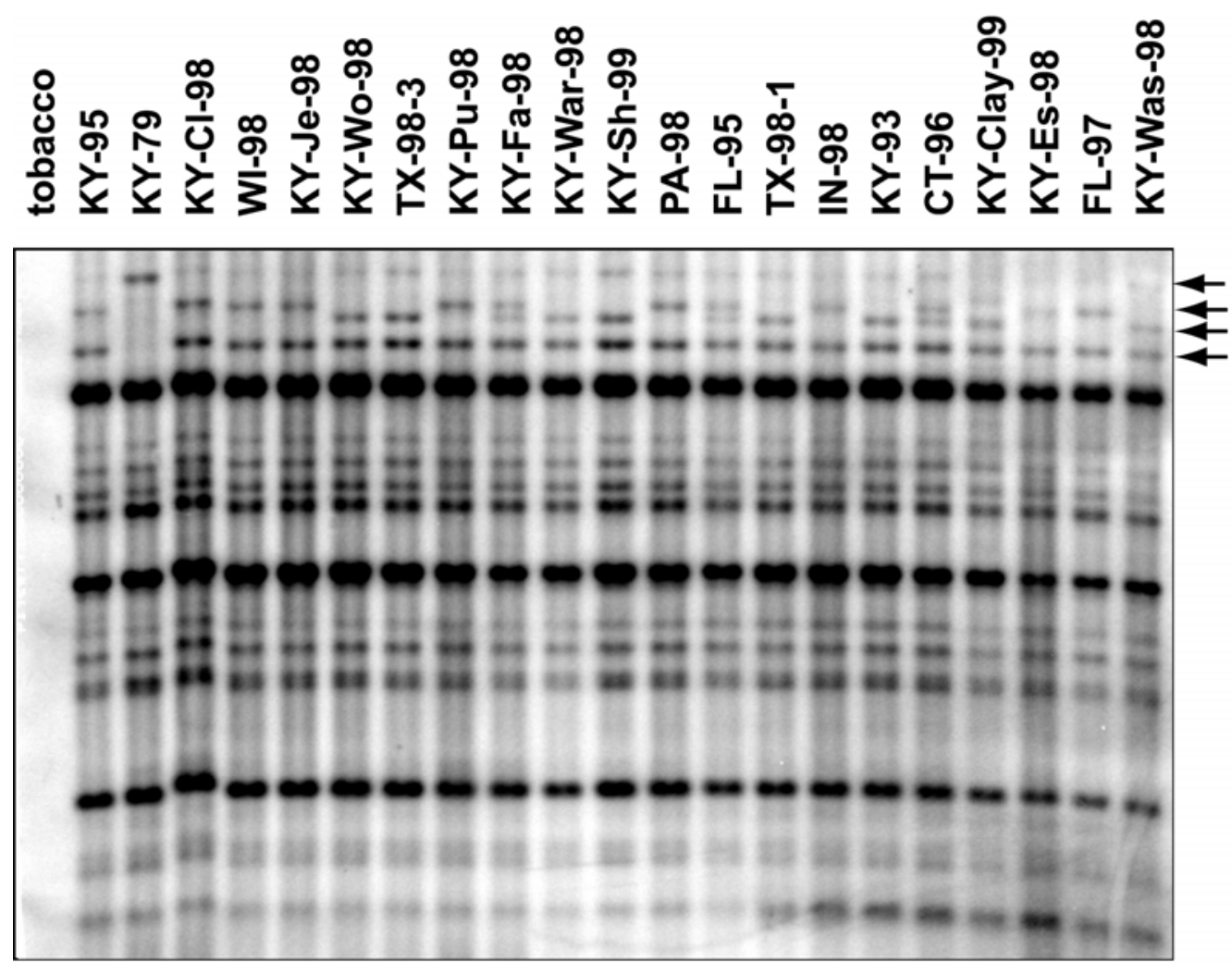

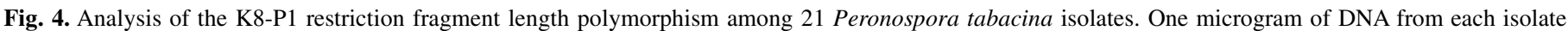

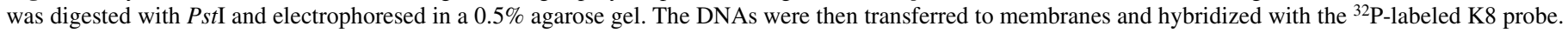

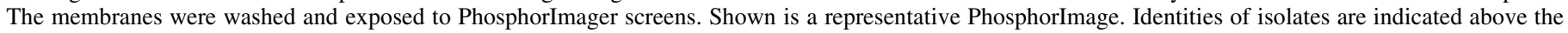
respective lanes, and tobacco DNA was included as a control (lane 1). Polymorphic fragments are indicated with arrows. 
is situated in Fayette County, where tobacco is the leading cash crop. Nevertheless, the molecular markers created in this study will provide valuable tools for future efforts to characterize the world $P$. tabacina population.

In addition to revealing a very low level of polymorphism in the pathogen population, the present study also provided some preliminary insights into the genetics of $P$. tabacina and its modes of reproduction. The moderately repetitive probes $\mathrm{K} 1$ and $\mathrm{K} 8$ identified loci that were homozygous in some individuals and heterozygous in others (Figs. 3 and 4). These results are consistent with the hypothesis that $P$. tabacina is diploid. This notion is also supported by the fact that other well-studied members of the Peronosporales are diploid (21). The fact that both homozygotes and heterozygotes were detected, together with the appearance of genotypes that are recombinant for certain marker pairs (e.g., K1D1 and K8-P1) (Table 3), indicates that genetic recombination does occur in the U.S. P. tabacina population. In this regard, it is significant that oospore-like structures have been detected in tobacco tissues infected with blue mold $(10,23,30)$. However, the lack of Hardy-Weinberg equilibrium at the K1-D1 and K8-P1 loci and evidence of linkage disequilibrium between some pairs of markers (Table 3) indicates that sexual reproduction is not the major determinant of $P$. tabacina population structure.

As a consequence of the low level of genetic variability in $P$. tabacina, we were unable to identify a large number of polymorphisms. Clearly, the availability of more markers would provide a greater power of resolution for differentiating isolates. Based on our results, it is evident that surveying for new RFLPs would be an inefficient way to identify additional markers. Targeting of loci with greater variability such as microsatellites (9) would likely be more successful. Importantly, microsatellites markers should be relatively insensitive to contaminating DNA as long as each one has previously been confirmed to be a true marker for $P$. tabacina.

Despite their small numbers, the markers identified in this study were quite useful for differentiating among isolates, enabling resolution of at least 10 genetically different forms of $P$. tabacina in the collection of isolates analyzed. A third of the isolates had haplotype C. Although this group occurred over a broad geographic area in 1998, there were at least five other haplotypes present in the United States that year. Three haplotypes were detected in Kentucky alone, indicating that the epidemic in this state was not caused by the spread of a single clone. Interestingly, our study found no correlation between the molecular haplotypes and metalaxyl sensitivity, even among isolates that appeared to be clones of one another. For example, WI-98, an isolate with haplotype C, was sensitive to metalaxyl, whereas all the other $\mathrm{C}$ isolates were resistant (data not shown). However, it should be noted that the fungicide tests were performed prior to this study and before the isolates were single-spored. Therefore, it is not possible to draw definitive conclusions from our findings in relation to fungicide resistance.

The markers that were identified in this study promise to be valuable for studying numerous aspects of $P$. tabacina population biology. For example, comparison of $P$. tabacina in the United States with isolates from around the globe could be used to determine if the current U.S. population was introduced from Cuba or elsewhere. In addition, the ability to identify specific $P$. tabacina haplotypes will allow inoculum sources to be identified as well as enabling specific isolates to be tracked during disease epidemics. This will provide a better understanding of the processes underlying the emergence of new pathogen races and the dynamics of disease development. Ultimately, this will lead to improved strategies for management of blue mold.

\section{ACKNOWLEDGMENTS}

This research was supported by a grant from the Tobacco \& Health Research Institute (THRI). This manuscript is Kentucky Agricultural
Experiment Station publication 02-12-122. We thank W. Nesmith for assistance and guidance in all aspects of this project; S. Dutton for teaching us how to culture P. tabacina; D. Thornbury and D. Brown for technical assistance; and M. Thon, W. Nesmith, and C. Schardl for editorial assistance and review of this manuscript.

\section{LITERATURE CITED}

1. Aylor, D. E., Taylor, G. S., and Raynor, G. S. 1982. Long-range transport of tobacco blue mold spores. Agric. Meteorol. 27:217-232.

2. Bruck, R. I., Guy, V., Gooding, J. R., and Main, C. E. 1982. Evidence for resistance to metalaxyl in isolates of Peronospora hyoscyami. Plant Dis. 66:44-45.

3. Dahmen, H., Staub, T., and Schwinn, F. J. 1983. Technique for long-term preservation of phytopathogenic fungi in liquid nitrogen. Phytopathology 73:241-246.

4. Edreva, A., Delon, R., and Coussirat, J. 1998. Variability of P. tabacina A. An isoenzyme study. Beitr. Tabakforsch. Int. 18:3-13.

5. Francis, D. M., Hulbert, S. H., and Michelmore, R. W. 1990. Genome size and complexity of the obligate fungal pathogen, Bremia lactucae. Exp. Mycol. 14:299-309.

6. Free, S. J., Rice, P. W., and Metzenberg, R. L. 1979. Arrangement of the genes coding for ribosomal ribonucleic acids in Neurospora crassa. J. Bacteriol. 137:1219-1226.

7. Freeman, S., Pham, M., and Rodriguez, R. 1993. Molecular genotyping of Colletotrichum species based on arbitrarily primed PCR, A+T-rich DNA, and nuclear analyses. Exp. Mycol. 17:309-322.

8. Goodwin, S. B., Drenth, A., and Fry, W. E. 1992. Cloning and genetic analysis of two highly polymorphic, moderately repetitive nuclear DNAs from Phytophthora infestans. Curr. Genet. 22:107-115.

9. Groppe, K., Sanders, I., Wiemken, A., and Boller, T. 1995. A microsatellite marker for studying the ecology and diversity of fungal endophytes (Epichloë spp.) in grasses. Appl. Environ. Microbiol. 61:39433949.

10. Heist, P. E., Nesmith, W. C., and Schardl, C. L. 2002. Interactions of Peronospora tabacina with roots of Nicotiana spp. in gnotobiotic associations. Phytopathology 92:400-405.

11. Kucharek, T. A., Young, T. R., and Thomas, W. D. 1996. Occurrences of some factors affecting blue mold of tobacco in Florida from 1921 to 1995. Soil Crop Sci. Soc. Flor. 55:81-85.

12. Kupiec, M., and Petes, T. D. 1988. Allelic and ectopic recombination between Ty elements in yeast. Genetics 119:549-559.

13. Kurdyla, T. M., Guthrie, P. A. I., McDonald, B. A., and Appel, D. N. 1995. RFLPs in mitochondrial DNA indicate low levels of genetic diversity in the oak wilt pathogen Ceratocystis fagacearum. Curr. Genet. 27:373-378.

14. Laurent, B. C., Yang, X., and Carlson, M. 1992. An essential Saccharomyces cerevisiae gene homologous to $S N F 2$ encodes a helicase-related protein in a new family. Mol. Cell. Biol. 12:1893-1902.

15. Lucas, G. B. 1980. The war against blue mold. Science 210:147-153.

16. Pipe, N. D., and Shaw, D. S. 1997. Telomere-associated restriction fragment length polymorphisms in Phytophthora infestans. Mol. Plant Pathol. On-line Publication no. 1997/1124pipe.

17. Raeder, U., and Broda, P. 1985. Rapid preparation of DNA from filamentous fungi. Lett. Appl. Microbiol. 1:17-20.

18. Rehmany, A. P., Lynn, J. R., Tor, M., Holub, E. B., and Beynon, J. L. 2000. A comparison of Peronospora parasitica (downy mildew) isolates from $A$. thaliana and B. oleracea using amplified fragment length polymorphisms and internal transcribed spacer1 sequence analyses. Fungal Genet. Biol. 30:95-103.

19. Reuveni, M., Nesmith, W. C., Siegel, M. R., and Keeny, T. M. 1988. Virulence of an endemic isolate of Peronospora tabacina from Texas to Nicotiana tabacum and N. repanda. Plant Dis. 72:1024-1027.

20. Rodriguez, R. J. 1983. Polyphosphate present in DNA preparations from filamentous fungal species of Colletotrichum inhibits restriction endonucleases and other enzymes. Anal. Biochem. 209:291-297.

21. Sansome, E., and Brasier, C. 1973. Diploidy and chromosomal structural hybridity in P. infestans. Nature 241:344-345.

22. Scherer, S., and Davis, R. W. 1980. Recombination of dispersed repeated DNA sequences in yeast. Science 209:1380-1384.

23. Spurr, H. W., and Todd, F. A. 1980. Observations of the extensive 1979 tobacco blue mold epidemic. Phytopathology 70:693.

24. Sukno, S. A., Taylor, A. M., and Farman, M. L. 2002. Development of contamination-free restriction fragment length polymorphism probes for the obligate biotroph Peronospora tabacina, an oomycete causing blue mold of tobacco. Phytopathology 92:1227-1235.

25. Tham, F. Y., Lucas, J. A., and Wilson, Z. A. 1994. DNA fingerprinting of Peronospora parasitica, a biotrophic fungal pathogen of crucifers. Theor. Appl. Genet. 88:490-496. 
26. Thornbury, D. W., and Farman, M. L. 2000. Re-use of nylon membranes for radioactive hybridizations. Biotechniques 29:1250-1254.

27. Wiglesworth, M. D. 1994. Differentiation and detection of Peronospora tabacina Adam. using the polymerase chain reaction. Ph.D. thesis. University of Kentucky, Lexington.

28. Wiglesworth, M. D., Reuveni, M., Nesmith, W. C., Siegel, M. R., Kuc, J., and Juarez, J. 1988. Resistance of Peronospora tabacina to metalaxyl in Texas and Mexico. Plant Dis. 72:964-967.

29. Wiglesworth, M. D., Schardl, C. L., Nesmith, W. C., and Siegel, M. R. 1991. Differentiation of Peronosporales and isolates of Peronospora tabacina by direct sequencing of an internal transcribed spacer (ITS2). Phytopathology 81:1237.

30. Wolf, F. A. 1947. Tobacco downy mildew, endemic to Texas and Mexico. Phytopathology 37:721-729. 